\title{
CONHECIMENTO BOTÂNICO LOCAL SOBRE MYRACRODRUON URUNDEUVA Allemão em seis comunidades rurais do semiárido da Paraíba, Nordeste DO BRASIL
}

\section{Carlos Antônio Belarmino Alves*1,4, João Everthon da Silva Ribeiro ${ }^{2}$, Natan Medeiros Guerra³ ${ }^{3}$ Mariana} Muniz Nunes ${ }^{4}$, Eduardo Uchôa Guerra Barbosa ${ }^{4}$, Ernane Nogueira Nunes ${ }^{4}$, Thamires Kelly Nunes Carvalho ${ }^{4}$, Camilla Marques de Lucena ${ }^{4,5}$, Jacob Silva Souto ${ }^{6}$, Reinaldo Farias Paiva de Lucena ${ }^{4}$.

\author{
1 Universidade Estadual da Paraíba. Campus III. Guarabira, Paraíba.E-mail para contato: c_belarminoalves@hotmail.com \\ 2 Programa de Pós-Graduação em Agronomia. Universidade Federal da Paraíba, Centro de Ciências Agrárias, Campus II, Areia, Paraíba. \\ 3 Programa de Pós-Graduação em Fitotecnia. Universidade Federal Rural do Semiárido, Mossoró, Rio Grande do Norte. \\ 4 Laboratório de Etnobiologia e Ciências Ambientais. Departamento de Sistemática e Ecologia. Centro de Ciências Exatas e da Natureza. Universidade \\ Federal da Paraíba, João Pessoa, Paraíba. \\ 5 Instituto de Educação Superior da Paraíba - IESP. Coordenação de Internacionalização. Cabedelo, Paraíba. \\ 6 Unidade Acadêmica de Engenharia Florestal. Universidade Federal de Campina Grande, Patos, Paraíba.
}

Recebido em 08 de julho de 2019. Aceito em 21 de julho de 2019. Publicado em 31 de julho de 2019.

\begin{abstract}
Resumo - Dentre as principais plantas inseridas no semiárido brasileiro, encontra-se a aroeira (Myracrodruon urundenva Allemão) pertencente à família Anacardiaceae, apresentando importância ecológica e econômica. A fim de entender e verificar tal importância, realizamos um estudo etnobotânico em seis comunidades do semiárido paraibano, utilizando formulários semiestruturados aplicados a populações locais. Registraram-se 1.587 citações de uso (856 citações atuais e 731 potenciais), sendo 985 de usos madeireiros e 602 não madeireiros para M. urundewva. Destacaram-se as categorias construção e combustível. Mediante os resultados do presente estudo, sugere-se que sejam realizadas pesquisas e monitoramento das populações dessa espécie nas áreas rurais, e com atividades voltadas para o manejo sustentável.
\end{abstract}

Palavras-chave: Caatinga, Etnobotânica, Ecologia.

Conocimiento botánico local sobre Myracrodruon urundeuva Allemão en seis comunidades rurales en la región semiárida de Paraíba, Noreste de Brasil

Resumen - Aroeira (Myracrodruon urundewva Allemão) es una de las plantas más importantes de la región semiárida de Brasil. Esta especie pertenece a la familia Anacardiaceae y tiene importancia ecológica y económica. Para la comprensión y verificación de tal importancia, se realizó un estudio etnobotánico utilizando cuestionarios semiestructurados aplicados a poblaciones locales en seis comunidades de la región semiárida de Paraíba. Se registraron 1.587 citas de uso (856 citas de uso actual y 731 citas de uso potencial), de las cuales 985 fueron para usos maderables y 602 para usos no maderables. Se destacaron las categorías de construcción y combustible. A partir de los resultados del presente estudio, se deben realizar investigaciones y monitoreo de esta especie en áreas rurales, con actividades dirigidas al manejo sostenible.

Palabras Clave: Caatinga, Etnobotánica, Ecología. 


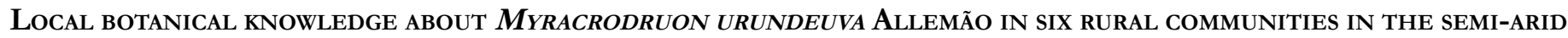
region of Paraíba, Northeast Brazil

Aвstract - Aroeira (Myracrodruon urundeuva Allemão) is one of the main plants in the semi-arid region of Brazil; it belongs to the family Anacardiaceae and has ecological and economic importance. Thus, with the purpose of understanding and verifying such importance, an ethnobotanical study was carried out using semi-structured questionnaires applied to local populations in six communities in the semi-arid region of Paraíba. A total of 1,587 use citations (856 current use citations and 731 potential use citations) were recorded, of which 985 were for timber and 602 were for non-timber uses. Construction and fuel were the most prominent categories. From the results of the present study, in-depth research and monitoring of this species should be carried out in rural areas, with activities aimed at sustainable management.

KEY Words: Caatinga, Ethnobotany, Ecology.

\section{INTRODUÇÃO}

A região semiárida do Nordeste do Brasil é considerada de grande importância, pois além de possuir uma dinâmica peculiar em sua vegetação (Araújo et al. 2007), apresenta uma rica biodiversidade (Silva et al. 2017), que vem sendo prospectada com os mais variados objetivos, sendo as propriedades medicinais a principal linha de investigação, o que vêm influenciando abordagens com foco conservacionista (Silva et al. 2012; Cavalcanti e Albuquerque 2013, Liporacci et al. 2017).

Estas prospecções abordam o conhecimento e a dinâmica de comunidades tradicionais como os quilombolas, ribeirinhos e habitantes do meio rural. Essas comunidades possuem um grande conhecimento sobre a vegetação na qual convivem, e com isso fornecem bases empíricas que colaboram com a ciência acadêmica, principalmente através de estudos etnobotânicos que buscam compreender a dinâmica das relações homem-planta (Ford 1978; Oliveira et al. 2009), conquistando resultados importantes, como, por exemplo, a descoberta de novos princípios ativos e indicando espécies que estejam sofrendo possíveis pressões de uso (Yunes et al. 2001; Cartaxo et al. 2010; Silva et al. 2011).

Uma das vegetações que tem sido utilizada pelas populações tradicionais ao longo do tempo, e investigada por especialistas, é a do semiárido, a qual é rica e diversa em princípios ativos para uso medicinal, o que pode ser compreendido pelo fato das plantas habitarem lugares com condições adversas e por isso necessitarem, constantemente, se defender, seja da agressão de pragas e doenças, raios solares intensos e as próprias recessões hídricas típicas da região, o que acaba gerando uma gama de produtos oriundos do metabolismo secundário, com as mais variadas atividades biológicas (Cuchillo et al. 2013).

Dentre as muitas espécies encontradas no semiárido do Nordeste, uma se destaca por apresentar enorme resistência e versatilidade, a aroeira (Myracrodruon urundeuva Allemão) (Pereira et al. 2014). Considerada uma espécie vegetal arbórea, pertencente à família Anacardiaceae, com distribuição restrita a América do Sul, sendo encontrada principalmente em áreas mais secas e em solos rochosos, em variadas faixas de altitude e condições climáticas, apresentando uma madeira bastante densa, sendo considerada nobre (Rizzini 1970; Lorenzi e Matos 2002; Carvalho 2003; Siqueira et al. 2012).

Devido a essas características, diversos estudos vêm evidenciando a amplitude de fins madeireiros e não madeireiros desta espécie, como o uso medicinal e para a construção das mais variadas estruturas rurais e domésticas (Albuquerque e Oliveira 2007; Oliveira et al. 2007; Ramos et al. 2008a; Machado et al. 2011; Pereira et al. 2014; Coutinho et al. 2015; Lima et al. 2015; Pedrosa et al. 2015; Lima et al. 2018), além de estar sendo estudada como participante de sistemas agroflorestais, conservação de recursos genéticos, estudos químicos e bioquímicos, 
principalmente por apresentar taninos e flavonoides, considerados importantes princípios ativos de drogas (NobreJúnior et al. 2009; Gaino et al. 2010; Siqueira et al. 2012).

Devido sua versatilidade, a aroeira necessita de constante monitoramento, ou poderá ingressar novamente na lista de espécies ameaçadas de extinção, onde encontra-se como levemente preocupante (Nature 2015), mesmo assim, constantemente vem sendo alvo de estudos que a valorizam e incitam a sua conservação por tamanha importância para as pessoas do meio onde a espécie existe (Leite 2002; Monteiro et al. 2012; Rodriguez et al. 2017).

Com base nas informações apresentadas na literatura sobre o uso e conservação das espécies vegetais encontradas na Caatinga, o presente estudo realizou uma análise regional sobre $M$. urundeuva, com base em informações coletadas em comunidades rurais de seis municípios do estado da Paraíba, sendo registrado e avaliado o conhecimento e usos atribuídos à mesma.

\section{Material e Métodos}

\section{Contexto regional e local de trabalho}

O presente estudo foi realizado no semiárido do estado da Paraíba, Nordeste do Brasil, em diferentes regiões de Caatinga. Foram visitadas e estudadas áreas em seis comunidades rurais: São Francisco no município de Cabaceiras, Santa Rita no Congo, Pau D’Arco em Itaporanga, Coelho em Remígio, Várzea Alegre em São Mamede e Capivara em Solânea, distribuídas entre a Depressão Sertaneja e o Planalto da Borborema (Figura 1).

Essas comunidades foram escolhidas em virtude de já existirem pesquisas etnobotânicas realizadas nestas áreas e por outras estarem em andamento pelo grupo de pesquisa em Etnobiologia e Ciências Ambientais do Centro de Ciências Exatas e da Natureza da Universidade Federal da Paraíba, o que facilitou o acesso aos moradores e a confiança nas informações fornecidas (Guerra et al. 2012; Leite et al. 2012; Lucena et al. 2012; Pedrosa et al. 2012; Sousa et al. 2012; Lucena et al. 2013; Lucena et al. 2014; Silva et al. 2014; Ribeiro et al. 2014).

Figura 1. Localização geográfica dos municípios de Cabaceiras, Congo, Itaporanga, Remígio, São Mamede e Solânea, Estado da Paraíba, Brasil.
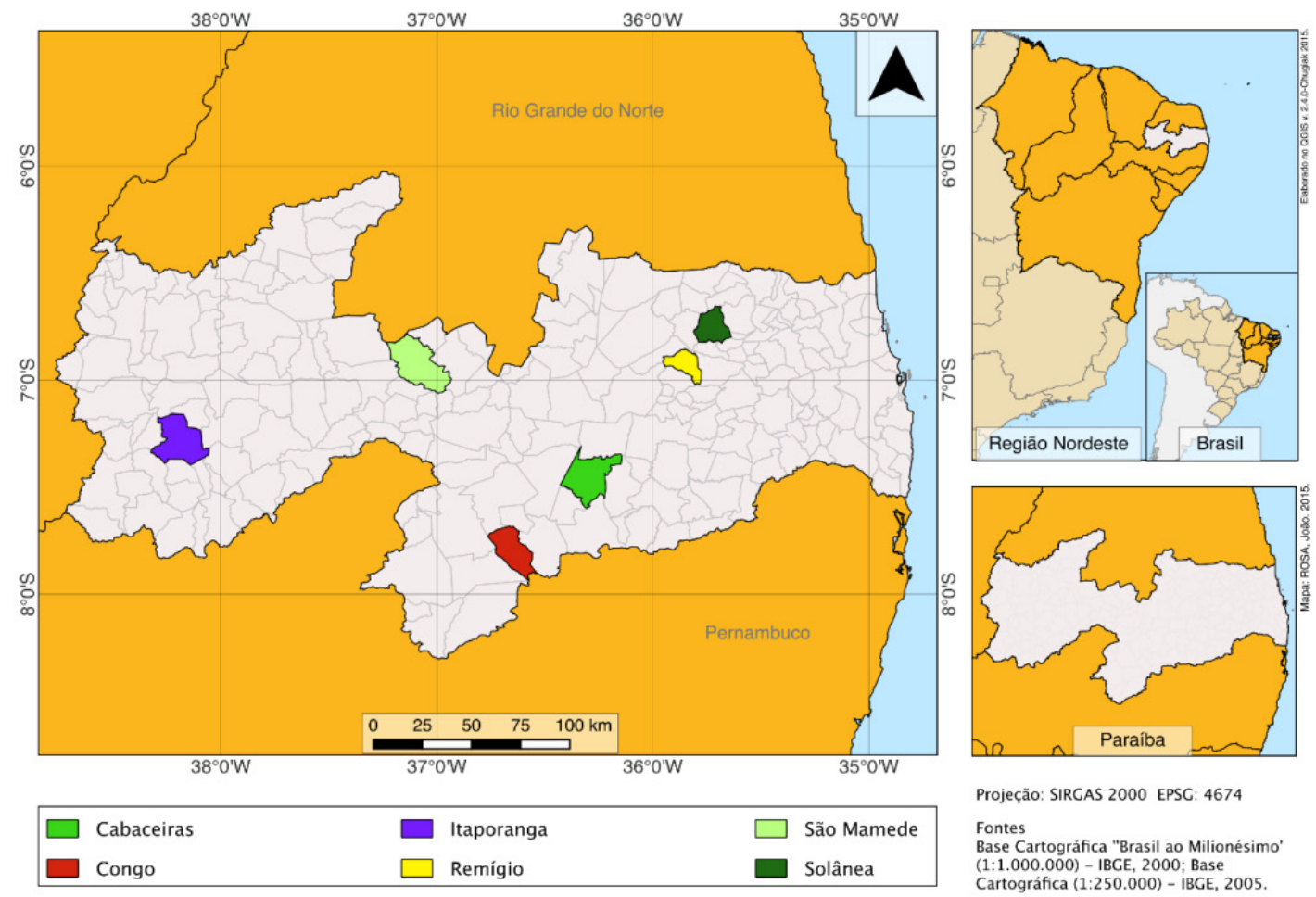
O município de Cabaceiras (7²9’20' S e 36¹7’14” O) localiza-se na Mesorregião da Borborema e Microrregião do Cariri Oriental, no Planalto da Borborema. Está aproximadamente a $210 \mathrm{~km}$ da capital do Estado, João Pessoa, abrangendo uma área de 452,922 km². Com 400 metros de altitude e clima caracterizado como "BSh" (semiárido quente), registra temperatura média anual superior a $20^{\circ} \mathrm{C}$, apresentando o menor índice pluviométrico do Brasil, com menos de $300 \mathrm{~mm}$ de chuva anual (IBGE 2010).

A comunidade de São Francisco e composta por cinco localidades: Alto Fechado, Caroatá de Dentro, Jerimum, Malhada Comprida e Rio Direito. Está a $18 \mathrm{~km}$ da sede do município, dispondo de uma capela da religião católica, um posto médico com atendimento duas vezes ao mês, sendo estes realizados em um salão localizado em Caroatá de Dentro. A economia local provém de atividades agropastoris com destaque para a criação de ruminantes, cultivos de milho e feijão, além outras culturas de subsistências (Silva et al. 2014; Lucena et al. 2013).

O município do Congo (0747’49'S e 36³9’36”O) se localiza na Mesorregião da Borborema e Microrregião do Cariri Ocidental, no Planalto da Borborema. Situando-se a aproximadamente a $276 \mathrm{~km}$ de João Pessoa, com altitude de 480 metros em uma área de $333,471 \mathrm{~km}^{2}$. Apresenta clima tropical semiárido com chuvas de verão “Aw", temperatura média em torno de $26^{\circ} \mathrm{C}$, pluviosidade média acima de $400 \mathrm{~mm}$.

A comunidade Santa Rita localiza-se a aproximadamente $8 \mathrm{~km}$ do centro urbano. Na comunidade existe um grupo escolar, que atualmente encontra-se desativado. Há presença de uma agente comunitário de saúde que faz o acompanhamento periódico dessas famílias, quando se trata das questões inerentes à saúde. Os estudantes que residem na comunidade deslocam-se para o centro urbano, via transporte escolar subsidiado pelo Município. A economia local tem como base a agricultura de subsistência, com destaque para cultura do milho e feijão e na pecuária a criação de bovinos, caprinos e ovinos em pequena escala (Lucena et al. 2013).

O município de Itaporanga ( $7^{\circ} 18^{\prime} 14^{\prime \prime}$ e $\left.38^{\circ} 09^{\prime} 00^{\prime} O\right)$ localiza-se na Mesorregião do Sertão e Microrregião do Vale do Piancó, na Depressão Sertaneja, distando 471 km de João Pessoa, abrange uma área territorial de 468,060 $\mathrm{km}^{2}$, com altitude de 191 metros. Apresenta clima semiárido quente "Aw", com temperatura média superior a $23^{\circ} \mathrm{C}$, de curta estação chuvosa, com chuvas de alta intensidade e baixa duração e pluviosidade acima dos $500 \mathrm{~mm}$ por ano (IBGE 2010).

A comunidade Pau D`Arco localiza-se a $8 \mathrm{~km}$ do centro urbano do município. Possui um campo para prática de futebol, capela da religião católica. A deficiência hídrica da região está sendo amenizada através da perfuração de poços artesianos, por meio de ação governamental, o que está movimentando a economia através da caprinovinocultura e plantios de culturas de subsistência (Sousa et al. 2012; Lucena et al. 2014; Leite et al. 2012; Pedrosa et al. 2012).

O município de Remígio (0654’10” S e 3550’02” O) está inserido na mesorregião do Agreste e microrregião do Curimataú Ocidental, no Planalto da Borborema. Apresenta território de 180,897 km² e localiza-se cerca de $151 \mathrm{~km}$ de João Pessoa. Possui altitude de 593 metros, com clima tipo tropical chuvoso com verão seco "Aw", temperatura média de $22^{\circ} \mathrm{C}$ e pluviosidade anual superior aos $700 \mathrm{~mm}$.

A comunidade Coelho está localizada a $9 \mathrm{~km}$ do centro urbano, sendo composta por pequenos produtores agropecuaristas, onde a atividade principal da região e o cultivo do milho e feijão, além da pecuária, com destaque para as criações de bovinos, caprinos e ovinos (Guerra et al. 2014).

O município de São Mamede (6 55’37”' S e 3705’45” O) localiza-se na mesorregião do Sertão Paraibano e microrregião do Seridó Ocidental, na Depressão Sertaneja. Apresenta uma área territorial de aproximadamente $530,728 \mathrm{~km}^{2}$ e a $326 \mathrm{~km}$ da capital do estado, João Pessoa. Altitude em torno de 263 metros, apresentando o clima, tipo "BSh" (semiárido quente) com chuvas de verão, temperatura média anual de $28^{\circ} \mathrm{C}$, pluviosidade média de 700 $\mathrm{mm}$ por ano.

A comunidade de Várzea Alegre localiza-se a $9 \mathrm{~km}$ do centro urbano do município, possui sua economia baseada na agropecuária com o cultivo de milho, feijão, algodão e a criação de bovinos, caprinos e ovinos (Lucena et al. 2012; Guerra et al. 2012; Pedrosa et al. 2012; Lucena et al. 2014). 
O município de Solânea (0646’40” S e 3541'49” O) está inserido na mesorregião do Agreste e microrregião do Curimataú Oriental, no Planalto da Borborema. Abrange uma área territorial de 232,096 $\mathrm{km}^{2}$, distanciando da capital do estado (João Pessoa) em aproximadamente $139 \mathrm{~km}$. Possui altitude de 626 metros, com clima tipo tropical chuvoso de verão seco "As", atingindo uma temperatura média anual em torno de $25^{\circ} \mathrm{C}$, pluviosidade média anual superior a $800 \mathrm{~mm}$ e vegetação composta por Caatinga subcaducifólia e caducifólia (IBGE 2010).

A comunidade Capivara localiza-se, aproximadamente a $15 \mathrm{~km}$ da sede do município. A economia predominante é a de agropecuária em pequena escala, com destaque para a agricultura de sequeiro como a cultura da mandioca, milho e feijão, e na pecuária a criação bovina, caprina e ovina (Soares et al. 2013; Guerra et al. 2014).

A vegetação encontrada na extensão das áreas de estudo são do tipo caatinga variando entre predomínio do extrato arbustivo/arbóreo, trechos de floresta caducifólia e subcaducifólia (IBGE 2010), de acordo com as modificações geográficas e de paisagem.

\section{Coleta E ANÁLISE DE DADOS}

Os dados etnobotânicos foram coletados por meio de entrevistas semiestruturadas com auxílio de formulário, sendo elaborados com perguntas parcialmente formuladas antes de sua aplicação, apresentando flexibilidade, o que permitiu o aprofundamento de elementos que foram surgindo ao longo das entrevistas (Albuquerque et al. 2010) permitindo a divisão em subcategorias.

Nas comunidades estudadas foram realizadas visitas em todas as residências habitadas, sendo explicado o objetivo do estudo, solicitando-se em seguida aos que concordaram participar da pesquisa, assinar o Termo de Consentimento Livre e Esclarecido exigido pelo Conselho Nacional de Saúde por meio do Comitê de Ética em Pesquisa (Resolução 196/96) no Brasil. Este estudo foi aprovado pelo Comitê de Ética em Pesquisa com Seres Humanos (CEP) do Hospital Lauro Wanderley da Universidade Federal da Paraíba, registrada com o protocolo CEP/HULW no 297/11.

Foram entrevistados $100 \%$ de todos os mantenedores da família, tanto os homens como as mulheres, totalizando 426 participantes (44,6\% homens e 55,4\% mulheres), sendo 123 em São Francisco (53 h e 70 m), 98 em Santa Rita (41h e 57m), 15 em Pau D’Arco (08h e 07m), 42 em Coelho (18h e 24m), 36 em Várzea Alegre (17h e $19 \mathrm{~m})$ e 112 em Capivara (53h e $59 \mathrm{~m})$. A diferença entre o número de homens e mulheres se deu porque, entrevistou-se só o homem e mulher separadamente, em virtude de as comunidades apresentarem pessoas com estado civil de viúvo (a) ou solteiro (a).

Para analisar os dados etnobotânicos foram consideradas apenas as informações das pessoas que durante as entrevistas afirmaram conhecer e atribuíram usos a M. urundeuva, já que alguns dos informantes não reconheceram ou não atribuíram usos as espécies. Nesse caso, apenas 317 informantes participaram dos 426 visitados, sendo 109 em São Francisco, 59 em Santa Rita, 11 em Pau D’Arco, 28 em Coelho, 15 informantes em Várzea Alegre e 95 na comunidade de Capivara, o que representa em média 74,41\% de todos os informantes.

O formulário utilizado nas entrevistas abordou perguntas específicas sobre a aroeira, visando registrar seus usos locais, bem como as categorias de uso da espécie. Estas categorias foram determinadas de acordo com a literatura etnobotânica especializada, sendo: Combustível, construção, forragem, medicinal, tecnologia, veterinária, ornamentação, veneno/abortiva e outros usos (Albuquerque e Andrade 2002a,b; Ferraz et al. 2006; Lucena et al. 2008; Lucena et al. 2012a,b).

$\mathrm{Na}$ categoria outros usos, foram incluídas as citações para bioindicadores de chuva (sinal de chuva) e sombreamento. Em cada categoria, as citações de uso foram divididas em subcategorias e classificadas em citações de uso atual (representado por todos os usos efetivos das plantas, excluindo os usos apenas conhecidos) e citações 
de uso potencial (são os usos que estão apenas no conhecimento das pessoas, mas com potencial de uso em necessidades emergenciais) (Lucena et al. 2012a) sendo esta distinção realizada no momento das entrevistas, quando era solicitado aos informantes que evidenciassem que tipos de usos fazem parte do seu cotidiano, descobrindo dessa forma os usos para cada espécie. Os usos foram organizados em usos madeireiros e não madeireiros para verificar qual dos tipos predominava nas comunidades.

Realizou-se coleta do material botânico, que foi posteriormente herborizado na forma de exsicata e indexado à coleção do Herbário Jaime Coelho de Moraes (EAN) do Centro de Ciências Agrárias da Universidade Federal da Paraíba (UFPB, Campus II), com o número de tombo 17632.

\section{Resultados e Discussão}

\section{Conbecimento e Usos}

Estudos vêm registrando o conhecimento e usos atribuídos à $M$. urundeuva pelas populações tradicionais, principalmente no semiárido nordestino (Albuquerque e Oliveira 2007; Albuquerque et al. 2011; Carvalho et al. 2012; Leite et al. 2012; Silva et al. 2014; Ribeiro et al. 2014; Coutinho et al. 2015; Lima et al. 2015; 2018). Buscando informações dessa natureza em outras áreas da Caatinga ainda não investigadas, registrou-se, no presente estudo, um total de 1.587 citações de usos para a espécie (Figura 2) em seis municípios, sendo 856 (53,93\%) de citações de uso atuais e $731(46,07 \%)$ potenciais, com 985 (62,06\%) de usos madeireiros e 602 (37,93\%) não madeireiros (Figura 3). O predomínio de usos madeireiros para essa espécie já vem sendo registrado nos estudos etnobotânicos, como por exemplo, o de Sousa et al. (2012), realizado no Sertão da Paraíba, onde registraram 87\% de citações de uso madeireiros, e o de Lucena et al. (2011), na região do Curimataú da Paraíba, onde também registraram, em duas comunidades rurais, uma porcentagem superior a $80 \%$ para esses usos.

Figura 2. Número de citações de uso geral, atual e potencial de Myracrodruon urundeuva Allemão (aroeira) nas comunidades de Capivara, Coelho, Pau D’Arco, Santa Rita, São Francisco e Várzea Alegre (Paraíba, Brasil).

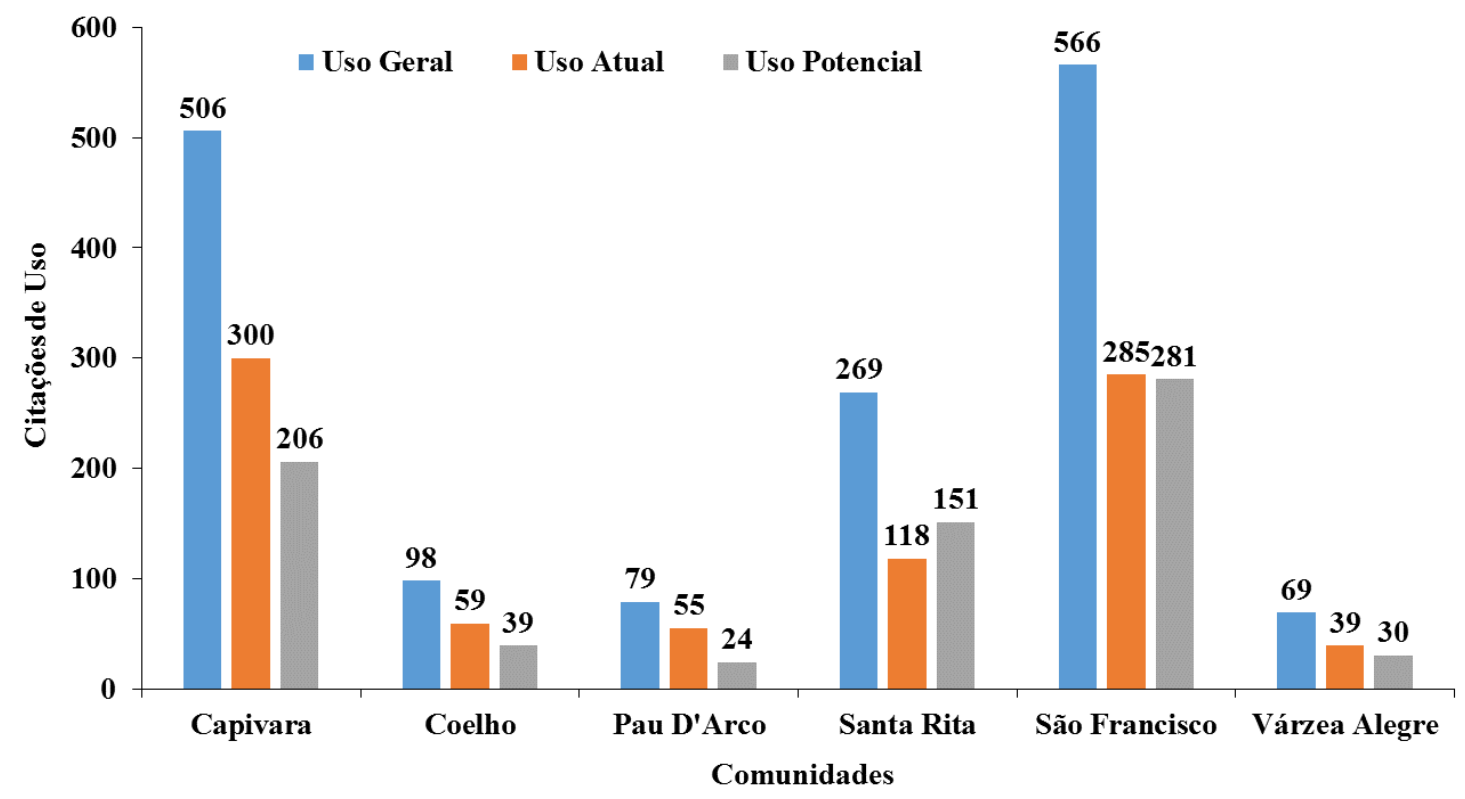


Figura 3. Divisão dos usos madeireiros e não madeireiro de Myracrodruon urundeuva Allemão, nas comunidades de Capivara, Coelho, Pau D’Arco, Santa Rita, São Francisco e Várzea Alegre (Paraíba, Brasil).

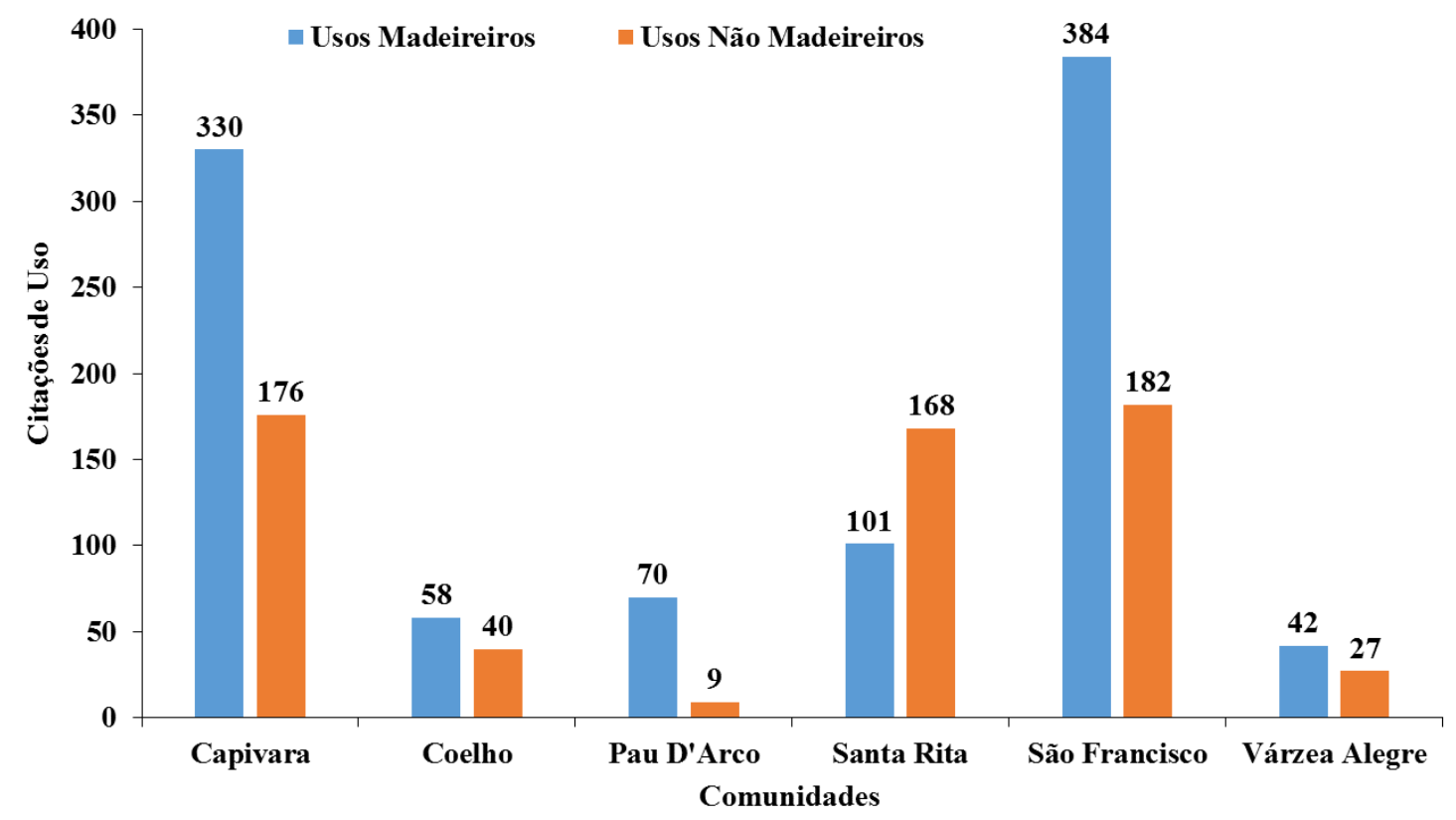

Comprovou-se no presente estudo o predomínio de citações de usos madeireiros sobre os não madeireiros, em quase todas as comunidades, exceto em Santa Rita (Tabelas 1, 2, 3, 4, 5 e 7). Mas, de modo geral, o predomínio de uso da espécie se dá, devido ao grande destaque das categorias construção e combustível, que demandam maiores quantidades de material vegetal, conforme estudo de Lucena et al. (2011), que evidenciaram os mesmos resultados no município de Soledade, também na Paraíba.

As citações de usos totais foram divididas em atuais e potenciais, onde as atuais destacaram-se dos potenciais em quase todas as comunidades, exceto, novamente na comunidade de Santa Rita (Figura 2). Com esta distinção, verificou-se a importante informação, ligada a conservação da espécie, tendo em vista que os usos potenciais estão apenas na memória dos informantes e os atuais, que podem causar uma possível pressão de uso, indicam que a espécie está sendo utilizada constantemente. Em um estudo realizado por Lucena et al. (2011), especificamente $\operatorname{com} M$. urundewva, registraram um destaque das citações de uso potencial corroborando com os resultados de Santa Rita.

A constatação supracitada deve ser interpretada como um guia para compreender a dinâmica de uso, podendo auxiliar em estudos mais conclusivos sobre a conservação local da espécie mediante extração, a exemplo de Rodriguez et al. (2017).

Classificando os usos mencionados pelosinformantes em categorias pode-se registrar a grande representatividade da categoria combustível nas citações totais registradas (Tabelas 1, 2, 3, 4, 5 e 6). Pesquisas recentes realizadas em diversas áreas do semiárido, também registraram o uso predominante da aroeira como fonte combustível (Lucena et al. 2008; 2011; Lucena et al. 2012a; Carvalho et al. 2012; Lucena et al. 2012b; Sousa et al. 2012; Silva et al. 2014; Guerra et al. 2015; Lima et al. 2018).

Tal uso pode ser explicado pela alta qualidade da madeira como fonte energética, conforme citado por Ramos et al. (2008b), em trabalho realizado no município de Caruaru, Pernambuco, onde a espécie foi citada como fonte atual de combustível, embora os informantes tenham afirmado que essa planta não está entre as preferidas para a queima, possivelmente por medo de infringirem alguma lei ambiental, mas mesmo assim, foram atribuídas características importantes como: alto valor calórico, longa duração, facilidade de coleta e reduzida produção de cinzas. Mais discussões sobre o uso doméstico da madeira e eficiência energética do carvão são realizadas por Medeiros et al. (2012) e Silva et al. (2018). 
Para a categoria construção, pode-se dividi-la em dois grupos, as construções rurais e domésticas (Tabelas 1, 2, 3, 4, 5 e 6), o que corrobora com outras investigações (Lucena et al. 2011; Lucena et al. 2012a,b; Sousa et al. 2012; Lima et al. 2015; 2018). O interesse no uso para esta categoria pode ser explicado devido à resistência da espécie ao ataque de decompositores, principalmente em madeiras coletadas de indivíduos mais velhos os quais apresentam maior resistência a incidência de fungos (Paes et al. 2004) e cupins (Sá et al. 2008; 2009).

A categoria tecnologia também contribui de forma significativa para as citações totais de usos madeireiros, onde foram registradas citações de uso da espécie em todas as comunidades estudadas, confirmando assim a utilidade da aroeira para as finalidades tecnológicas (Tabelas 1, 2, 3, 4, 5 e 6), corroborando com trabalhos realizados no semiárido paraibano (Lucena et al. 2011; Lucena et al. 2012a,b; Sousa et al. 2012; Silva et al. 2014). Paes et al. (2004), destacaram que outra característica conferida a espécie na categoria construção é a densidade elevada da madeira, que confere também maior durabilidade, como por exemplo, em móveis.

Ressalta-se que as citações de uso atual são mais numerosas para todas as categorias, podendo indicar tanto, grande potencial utilitário da espécie, como afirmam Pereira et al. (2014), quanto o uso efetivo dentro das comunidades, representando a necessidade de estudos ecológicos específicos para inferir a sustentabilidade desse uso.

Tabela 1. Distribuição de citações de uso de aroeira (Myracrodruon urundeuva Allemão) em categorias e subcategorias de uso por moradores da comunidade rural de Várzea Alegre, município de São Mamede, Estado da Paraíba, Brasil.

\begin{tabular}{|c|c|c|c|c|c|c|c|}
\hline \multicolumn{8}{|c|}{ Várzea Alegre } \\
\hline Categoria & $\begin{array}{l}\text { Número } \\
\text { citações }\end{array}$ & $\begin{array}{l}\text { Uso } \\
\text { Atual }\end{array}$ & $\begin{array}{c}\text { Uso } \\
\text { Potencial }\end{array}$ & Subcategoria & $\begin{array}{l}\text { Número } \\
\text { citações }\end{array}$ & $\begin{array}{l}\text { Uso } \\
\text { Atual }\end{array}$ & $\begin{array}{c}\text { Uso } \\
\text { Potencial }\end{array}$ \\
\hline \multirow{2}{*}{ Combustível } & \multirow{2}{*}{8} & \multirow{2}{*}{4} & \multirow{2}{*}{4} & Lenha & 5 & 3 & 2 \\
\hline & & & & Carvão & 3 & 1 & 2 \\
\hline \multirow{10}{*}{ Construção } & \multirow{10}{*}{25} & \multirow{10}{*}{11} & \multirow{10}{*}{14} & Caxi de porta & 2 & 1 & 1 \\
\hline & & & & Caibro & 1 & - & 1 \\
\hline & & & & Estaca & 2 & 1 & 1 \\
\hline & & & & Forquilha & 2 & 1 & 1 \\
\hline & & & & Janela & 1 & - & 1 \\
\hline & & & & Linha & 7 & 2 & 5 \\
\hline & & & & Mourão & 7 & 5 & 2 \\
\hline & & & & Ripa & 1 & - & 1 \\
\hline & & & & Porta & 1 & - & 1 \\
\hline & & & & Suleira & 1 & 1 & - \\
\hline Forragem & 2 & 2 & - & - & - & 2 & - \\
\hline Medicinal & 24 & 18 & 6 & - & - & 18 & 6 \\
\hline \multirow{4}{*}{ Tecnologia } & \multirow{4}{*}{8} & \multirow{4}{*}{3} & \multirow{4}{*}{5} & Carro de boi & 1 & - & 1 \\
\hline & & & & Carroça de boi & 1 & - & 1 \\
\hline & & & & Móveis & 4 & 2 & 2 \\
\hline & & & & $\begin{array}{l}\text { Torno de } \\
\text { parede }\end{array}$ & 2 & 1 & 1 \\
\hline Ornamentação & 1 & - & 1 & - & - & - & 1 \\
\hline Outros usos & 1 & 1 & - & Bioindicação & 1 & 1 & - \\
\hline
\end{tabular}


Tabela 2. Distribuição de citações de uso de aroeira (Myracrodruon urundeuva Allemão) em categorias e subcategorias de uso por moradores da comunidade rural de Capivara, município do Solânea, Estado da Paraíba, Brasil.

\begin{tabular}{|c|c|c|c|c|c|c|c|}
\hline \multicolumn{8}{|c|}{ Capivara } \\
\hline Categoria & $\begin{array}{l}\text { Número } \\
\text { citações }\end{array}$ & $\begin{array}{l}\text { Uso } \\
\text { Atual }\end{array}$ & $\begin{array}{c}\text { Uso } \\
\text { Potencial }\end{array}$ & Subcategoria & $\begin{array}{l}\text { Número } \\
\text { citações }\end{array}$ & $\begin{array}{l}\text { Uso } \\
\text { Atual }\end{array}$ & $\begin{array}{c}\text { Uso } \\
\text { Potencial }\end{array}$ \\
\hline \multirow{2}{*}{ Combustível } & \multirow{2}{*}{124} & \multirow{2}{*}{58} & \multirow{2}{*}{66} & Lenha & 65 & 37 & 28 \\
\hline & & & & Carvão & 59 & 21 & 38 \\
\hline \multirow{15}{*}{ Construção } & \multirow{15}{*}{154} & \multirow{15}{*}{84} & \multirow{15}{*}{70} & Caxi de porta & 2 & 1 & 1 \\
\hline & & & & Caibro & 2 & - & 2 \\
\hline & & & & Estaca & 28 & 19 & 9 \\
\hline & & & & Forquilha & 9 & 4 & 5 \\
\hline & & & & Janela & 3 & 1 & 2 \\
\hline & & & & Linha & 57 & 30 & 27 \\
\hline & & & & Mourão & 29 & 17 & 12 \\
\hline & & & & Porta & 7 & 2 & 5 \\
\hline & & & & Porteira & 8 & 6 & 2 \\
\hline & & & & Tábua & 1 & - & 1 \\
\hline & & & & Curral & 1 & - & 1 \\
\hline & & & & Chomel & 1 & - & 1 \\
\hline & & & & Forro de porta & 1 & 1 & - \\
\hline & & & & Esteio & 3 & 1 & 2 \\
\hline & & & & Vara & 2 & 2 & - \\
\hline Forragem & 13 & 8 & 5 & - & - & 8 & 5 \\
\hline Medicinal & 141 & 124 & 17 & - & - & 124 & 17 \\
\hline \multirow{13}{*}{ Tecnologia } & \multirow{13}{*}{52} & \multirow{13}{*}{8} & \multirow{13}{*}{44} & Carroça de boi & 1 & 1 & - \\
\hline & & & & Móveis & 14 & 2 & 12 \\
\hline & & & & $\begin{array}{l}\text { Cabo de } \\
\text { ferramenta }\end{array}$ & 14 & 1 & 13 \\
\hline & & & & $\begin{array}{c}\text { Torno de } \\
\text { parede }\end{array}$ & 3 & - & 3 \\
\hline & & & & Canga de boi & 1 & - & 1 \\
\hline & & & & Canguita & 1 & 1 & - \\
\hline & & & & $\begin{array}{c}\text { Carroça de } \\
\text { burro }\end{array}$ & 1 & 1 & - \\
\hline & & & & Colher de pau & 1 & - & 1 \\
\hline & & & & Mão de pilão & 5 & - & 5 \\
\hline & & & & Gamela & 1 & & 1 \\
\hline & & & & Cruz de igreja & 1 & - & 1 \\
\hline & & & & Pilão & 8 & 2 & 6 \\
\hline & & & & Tacho & 1 & - & 1 \\
\hline Veterinário & 13 & 12 & 1 & - & - & 12 & 1 \\
\hline Outros usos & 8 & 5 & 3 & Sombra & 8 & 5 & 3 \\
\hline
\end{tabular}


Tabela 3. Distribuição de citações de uso de aroeira (Myracrodruon urundeuva Allemão) em categorias e subcategorias de uso por moradores da comunidade rural de Coelho, município de Remígio, Estado da Paraíba, Brasil.

\begin{tabular}{|c|c|c|c|c|c|c|c|}
\hline \multicolumn{8}{|c|}{ Coelho } \\
\hline Categoria & $\begin{array}{l}\text { Número } \\
\text { citações }\end{array}$ & $\begin{array}{c}\text { Uso } \\
\text { Atual }\end{array}$ & $\begin{array}{c}\text { Uso } \\
\text { Potencial }\end{array}$ & Subcategoria & $\begin{array}{l}\text { Número } \\
\text { citações }\end{array}$ & $\begin{array}{l}\text { Uso } \\
\text { Atual }\end{array}$ & $\begin{array}{c}\text { Uso } \\
\text { Potencial }\end{array}$ \\
\hline \multirow{2}{*}{ Combustível } & \multirow{2}{*}{19} & \multirow{2}{*}{13} & \multirow{2}{*}{6} & Lenha & 10 & 7 & 3 \\
\hline & & & & Carvão & 9 & 6 & 3 \\
\hline \multirow{5}{*}{ Construção } & \multirow{5}{*}{21} & \multirow{5}{*}{8} & \multirow{5}{*}{13} & Forquilha & 1 & - & 1 \\
\hline & & & & Linha & 5 & 3 & 2 \\
\hline & & & & Porta & 2 & - & 2 \\
\hline & & & & Cerca & 12 & 4 & 8 \\
\hline & & & & Taipa & 1 & 1 & - \\
\hline Forragem & 3 & 2 & 1 & - & - & 2 & 1 \\
\hline Medicinal & 33 & 25 & 8 & - & - & 25 & 8 \\
\hline \multirow{5}{*}{ Tecnologia } & \multirow{5}{*}{8} & \multirow{5}{*}{3} & \multirow{5}{*}{5} & Cabo de ferramenta & 3 & 1 & 2 \\
\hline & & & & Forquilha & 1 & 1 & - \\
\hline & & & & Móveis & 2 & 1 & 1 \\
\hline & & & & Pau de cangalha & 1 & - & 1 \\
\hline & & & & Porteira & 1 & - & 1 \\
\hline Veterinário & 5 & 3 & 2 & - & - & 3 & 2 \\
\hline
\end{tabular}

Tabela 4. Distribuição de citações de uso de aroeira (Myracrodruon urundeuva Allemão) em categorias e subcategorias de uso por moradores da comunidade rural de São Francisco, município de Cabaceiras, Estado da Paraíba, Brasil.

\begin{tabular}{|c|c|c|c|c|c|c|c|}
\hline \multicolumn{8}{|c|}{ São Francisco } \\
\hline Categoria & $\begin{array}{l}\text { Número } \\
\text { citações }\end{array}$ & $\begin{array}{l}\text { Uso } \\
\text { Atual }\end{array}$ & $\begin{array}{c}\text { Uso } \\
\text { Potencial }\end{array}$ & Subcategoria & $\begin{array}{l}\text { Número } \\
\text { citações }\end{array}$ & $\begin{array}{l}\text { Uso } \\
\text { Atual }\end{array}$ & $\begin{array}{c}\text { Uso } \\
\text { Potencial }\end{array}$ \\
\hline \multirow{2}{*}{ Combustível } & \multirow{2}{*}{147} & \multirow{2}{*}{61} & \multirow{2}{*}{86} & Lenha & 76 & 35 & 41 \\
\hline & & & & Carvão & 71 & 26 & 45 \\
\hline \multirow{11}{*}{ Construção } & \multirow{11}{*}{180} & \multirow{11}{*}{87} & \multirow{11}{*}{93} & Caxi de porta & 1 & 1 & - \\
\hline & & & & Caibro & 6 & 2 & 4 \\
\hline & & & & Estaca & 50 & 34 & 16 \\
\hline & & & & Forquilha & 5 & 1 & 1 \\
\hline & & & & Linha & 66 & 26 & 40 \\
\hline & & & & Mourão & 38 & 19 & 19 \\
\hline & & & & Ripa & 4 & 1 & 3 \\
\hline & & & & Porta & 6 & - & 6 \\
\hline & & & & Suleira & 1 & 1 & - \\
\hline & & & & Vara & 2 & 2 & - \\
\hline & & & & Porteira & 1 & - & 1 \\
\hline
\end{tabular}




\begin{tabular}{|c|c|c|c|c|c|c|c|}
\hline \multicolumn{8}{|c|}{ São Francisco } \\
\hline Categoria & $\begin{array}{l}\text { Número } \\
\text { citações }\end{array}$ & $\begin{array}{l}\text { Uso } \\
\text { Atual }\end{array}$ & $\begin{array}{c}\text { Uso } \\
\text { Potencial }\end{array}$ & Subcategoria & $\begin{array}{l}\text { Número } \\
\text { citações }\end{array}$ & $\begin{array}{l}\text { Uso } \\
\text { Atual }\end{array}$ & $\begin{array}{c}\text { Uso } \\
\text { Potencial }\end{array}$ \\
\hline Forragem & 72 & 44 & 28 & - & - & 44 & 28 \\
\hline Medicinal & 95 & 68 & 27 & - & - & 68 & 27 \\
\hline \multirow{9}{*}{ Tecnologia } & \multirow{9}{*}{57} & \multirow{9}{*}{13} & \multirow{9}{*}{44} & Carroça de boi & 4 & 1 & 3 \\
\hline & & & & Móveis & 7 & - & 7 \\
\hline & & & & Cabo de ferramenta & 18 & 5 & 13 \\
\hline & & & & Torno de parede & 16 & 5 & 11 \\
\hline & & & & Canga I & 1 & - & 1 \\
\hline & & & & Canga II & 7 & 1 & 6 \\
\hline & & & & Gamela & 1 & - & 1 \\
\hline & & & & Mão de pilão & 1 & - & 1 \\
\hline & & & & Pilão & 2 & 1 & 1 \\
\hline Veterinário & 3 & 3 & - & & - & 3 & - \\
\hline Ornamentação & 1 & 1 & - & - & - & 1 & - \\
\hline Outros usos & 11 & 8 & 3 & Sombra & 11 & 8 & 3 \\
\hline
\end{tabular}

Tabela 5. Distribuição de citações de uso de aroeira (Myracrodruon urundeuva Allemão) em categorias e subcategorias de uso por moradores da comunidade rural de Pau D’Arco, município de Itaporanga, Estado da Paraíba, Brasil.

\begin{tabular}{|c|c|c|c|c|c|c|c|}
\hline \multicolumn{8}{|c|}{ Pau D'Arco } \\
\hline Categoria & $\begin{array}{l}\text { Número } \\
\text { citações }\end{array}$ & $\begin{array}{l}\text { Uso } \\
\text { Real }\end{array}$ & $\begin{array}{c}\text { Uso } \\
\text { Potencial }\end{array}$ & Subcategoria & $\begin{array}{l}\text { Número } \\
\text { citações }\end{array}$ & $\begin{array}{l}\text { Uso } \\
\text { Atual }\end{array}$ & $\begin{array}{c}\text { Uso } \\
\text { Potencial }\end{array}$ \\
\hline \multirow{2}{*}{ Combustível } & \multirow{2}{*}{15} & \multirow{2}{*}{15} & \multirow{2}{*}{0} & Lenha & 7 & 7 & 0 \\
\hline & & & & Carvão & 7 & 7 & 0 \\
\hline \multirow{6}{*}{ Construção } & \multirow{6}{*}{41} & \multirow{6}{*}{26} & \multirow{6}{*}{15} & Caibro & 3 & 1 & 2 \\
\hline & & & & Cerca & 18 & 17 & 1 \\
\hline & & & & Forquilha & 11 & 6 & 5 \\
\hline & & & & Linha & 6 & 2 & 4 \\
\hline & & & & Porteira & 2 & 0 & 2 \\
\hline & & & & Ripa & 1 & 0 & 1 \\
\hline Forragem & 1 & 1 & 0 & & 1 & 1 & 0 \\
\hline Medicinal & 7 & 4 & 3 & & 7 & 4 & 3 \\
\hline \multirow{6}{*}{ Tecnologia } & \multirow{6}{*}{14} & \multirow{6}{*}{8} & \multirow{6}{*}{6} & Ancoreta & 1 & 1 & 0 \\
\hline & & & & Banco & 1 & 1 & 0 \\
\hline & & & & $\begin{array}{c}\text { Cabo de } \\
\text { Ferramenta }\end{array}$ & 6 & 6 & 0 \\
\hline & & & & $\begin{array}{c}\text { Canga de } \\
\text { Carroça } \\
\end{array}$ & 1 & 0 & 1 \\
\hline & & & & $\begin{array}{l}\text { Canga de } \\
\text { Cultivador }\end{array}$ & 1 & 0 & 1 \\
\hline & & & & Cangalha & 4 & 0 & 4 \\
\hline Veterinário & 1 & 1 & 0 & & 1 & 1 & 0 \\
\hline
\end{tabular}


Tabela 6. Distribuição de citações de uso de aroeira (Myracrodruon urundeuva Allemão) em categorias e subcategorias de uso por moradores da comunidade rural de Santa Rita, município de Congo, Estado da Paraíba, Brasil.

\begin{tabular}{|c|c|c|c|}
\hline \multicolumn{4}{|c|}{ Santa Rita } \\
\hline Categoria & Número de citações & Subcategoria & Número de citações \\
\hline \multirow{2}{*}{ Combustível } & \multirow{2}{*}{45} & Lenha & 23 \\
\hline & & Carvão & 22 \\
\hline \multirow{12}{*}{ Construção } & \multirow{12}{*}{87} & Caibro & 3 \\
\hline & & Caxi de Porta & 6 \\
\hline & & Estaca & 17 \\
\hline & & Forquilha & 3 \\
\hline & & Janela & 4 \\
\hline & & Linha & 23 \\
\hline & & Mourão & 17 \\
\hline & & Pontalete & 1 \\
\hline & & Porta & 6 \\
\hline & & Porteira & 4 \\
\hline & & Ripa & 1 \\
\hline & & Vara & 2 \\
\hline Forragem & 16 & - & - \\
\hline Medicinal & 63 & - & - \\
\hline \multirow{12}{*}{ Tecnologia } & \multirow{12}{*}{48} & $\begin{array}{c}\text { Cabo de } \\
\text { Ferramenta }\end{array}$ & 7 \\
\hline & & Canga de Boi & 4 \\
\hline & & $\begin{array}{c}\text { Canga de } \\
\text { Carroça }\end{array}$ & 1 \\
\hline & & $\begin{array}{l}\text { Canga de } \\
\text { Cultivador }\end{array}$ & 2 \\
\hline & & Cangalha & 1 \\
\hline & & Carro de Boi & 4 \\
\hline & & Desempoladeira & 1 \\
\hline & & $\begin{array}{c}\text { Eixo de Carro de } \\
\text { Boi }\end{array}$ & 2 \\
\hline & & Mão de Pilão & 1 \\
\hline & & Móvel & 12 \\
\hline & & Pilão & 4 \\
\hline & & Torno de Parede & 9 \\
\hline Veterinário & 7 & - & \\
\hline \multirow{2}{*}{ Outros usos } & \multirow{2}{*}{3} & Sombra & 2 \\
\hline & & Bioindicador & 1 \\
\hline
\end{tabular}

A categoria medicinal (Tabela 7) apresentou grande importância nas comunidades estudadas, com exceção de Pau D’Arco, destacando-se entre as três categorias que mais receberam citações de uso, o que se assemelhou aos resultados de Monteiro et al. (2012), onde mais de 75\% dos informantes afirmaram só conhecerem a aroeira para fins medicinais.

As utilizações medicinais e indicações terapêuticas da aroeira, segundo o conhecimento das comunidades estudadas nesse estudo, foram registradas no tratamento de 69 patologias. A extração da casca é a principal prática 
para fins medicinais, sendo comum na região do semiárido (Albuquerque et al. 2011). A categoria medicinal, apesar de não ser uma categoria madeireira, apresenta implicações na conservação da espécie, tendo em vista que a extração indiscriminada da casca pode ocasionar a morte dos indivíduos (Albuquerque e Oliveira 2007; Pedrosa et al. 2015).

Diversos trabalhos etnobotânicos vêm registrando os usos medicinais da aroeira (Viana et al. 2003; Albuquerque e Oliveira 2007; Lucena et al. 2011; Carvalho et al. 2012; Lucena et al. 2012a,b; Sousa et al. 2012; Cecílio et al. 2016; Oliveira et al. 2017; Galvão et al. 2018). Silva et al. (2012), avaliaram a ação anti-inflamatória e analgésica de extrato retirado do caule da aroeira em ratos, e comprovaram maior eficiência para a aplicação intraperitoneal e menor quando ministrado de forma oral.

Pereira et al. (2014) e Oliveira et al. (2017), evidenciaram o uso da espécie como cicatrizante e no tratamento de pruridos e no tratamento de fungos (Candida) vaginais, confecção de sabonete, cozimentos, chás e infusões, citados no trabalho os quais são utilizados no combate as inflamações de garganta e gastrites, sendo o extrato e tintura usados como cicatrizante. Em estudo sobre o uso e diversidade de plantas medicinais no Quilombo Olho D’agua dos Pires, Franco e Barros (2006), relataram o uso de chá no tratamento da gastrite, e garrafadas contendo M. urundewva para inflamações, assemelhando-se com o trabalho de Albuquerque e Andrade (2002), que afirmam que a aroeira é utilizada externamente contra inflamações e pancadas e no alivio da gastrite.

Silva et al. (2006), mostram o uso da entrecasca de aroeira como agente anti-inflamatório e cicatrizante utilizado no tratamento de inflamações ginecológicas, anti-histamínico e anti-bradicinínico utilizado no tratamento de gastrite e úlcera gástrica. Cartaxo et al. (2010), também fazem citações do uso da aroeira no tratamento de doenças uterinas, renais, e ainda como anti-inflamatório, tratamento de câncer, cistos ovarianos, coceira, gripe, lesões, dor de dente e pernas, gastrite, úlceras, infecção urinária, como expectorante, inflamação dentária, inflamação em mulheres, inflamação na garganta e do útero, inchaço nos membros inferiores, problemas hepáticos, próstata, queimaduras, tosse e vermes (Silva et al. 2014).

Galvão et al. (2018), além do olhar da bioprospecção em detrimento do potencial medicinal da aroeira também argumentam a possibilidade de pensar na sua conservação, quando propõe a associação de substâncias químicas associadas ao potencial gastroprotetivo e anti-inflamatório. 


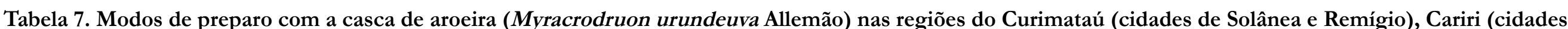

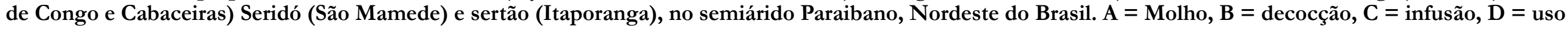
tópico, $\mathrm{E}=$ lambedor, $\mathrm{F}=$ banho de assento, $\mathrm{G}=$ garrafada e $\mathrm{H}=$ Defumado

\begin{tabular}{|c|c|c|c|c|c|c|c|c|c|c|c|}
\hline Cabaceiras & Preparo & Congo & Preparo & Itaporanga & Preparo & Remígio & Preparo & São Mamede & Preparo & Solânea & Preparo \\
\hline Inflamação geral & $\mathrm{A}, \mathrm{B}, \mathrm{D}, \mathrm{G}$ & Mal-estar & G & Inflamação geral & A & Dor & A, B, G & $\begin{array}{c}\text { Orquite pós- } \\
\text { caxumba }\end{array}$ & $\mathrm{H}$ & Inflamação geral & $\begin{array}{c}\text { A, B, C, } \\
\text { D, E }\end{array}$ \\
\hline \multirow[t]{4}{*}{ Pancada } & A, B & Dor & A & & & Inflamação geral & A, B, C, E, G & Inflamação geral & A & $\begin{array}{c}\text { Infecção } \\
\text { bacteriana }\end{array}$ & A \\
\hline & & Ressaca & G & & & Mal-estar & B & & & Dor & A \\
\hline & & $\begin{array}{c}\text { Inflamação } \\
\text { geral }\end{array}$ & A, F, & & & Pancada & A, B & & & Pancada & A, B \\
\hline & & Pancada & B & & & & & & & & \\
\hline- & - & - & - & - & & Falta de apetite & $\mathrm{B}$ & - & - & & \\
\hline Problemas Renais & A & Fígado & G & - & & $\begin{array}{l}\text { Problemas } \\
\text { renais }\end{array}$ & A, B, C, G & Problemas renais & A & & \\
\hline \multirow[t]{2}{*}{ Dor na coluna } & A & - & - & - & - & Reumatismo & A, B & Dor na coluna & A & Dor na coluna & A \\
\hline & & & & & & $\begin{array}{l}\text { Afecções } \\
\text { articulares }\end{array}$ & A, B & & & & \\
\hline \multirow[t]{4}{*}{ Ferimento } & A, B, C, D & Ferimento & A, B, D & Ferimento & A, D & Ferimento & $\mathrm{A}, \mathrm{B}, \mathrm{D}, \mathrm{F}$ & Ferimento & A, D & Ferimento & A, B, D \\
\hline & & & & & & Queima dura & $\mathrm{D}$ & & & & \\
\hline & & & & & & Caspa & $\mathrm{D}$ & & & Mancha dérmica & $\mathrm{D}$ \\
\hline & & & & & & & & & & Prurido & $\mathrm{D}$ \\
\hline Gastrite & A & Úlcera & G & & & & & & & Afecções dentárias & A, B, D \\
\hline Afecção dentária & A, B, D & $\begin{array}{l}\text { Inflamação } \\
\text { na garganta }\end{array}$ & A, D & - & - & Afecção dentária & A, B & $\begin{array}{c}\text { Inflamação na } \\
\text { garganta }\end{array}$ & A & Gastrite & A, B, D \\
\hline \multirow[t]{5}{*}{$\begin{array}{c}\text { Inflamação na } \\
\text { garganta }\end{array}$} & A, B, D & $\begin{array}{l}\text { Afecção } \\
\text { dentária }\end{array}$ & A & & & Dor de barriga & A, B, D & Gastrite & A & Úlcera & A \\
\hline & & Gastrite & A, B & & & Gases & $\mathrm{B}$ & & & & \\
\hline & & & & & & Úlcera & B & & & & \\
\hline & & & & & & $\begin{array}{c}\text { Inflamação } \\
\text { gengival }\end{array}$ & B & & & & \\
\hline & & & & & & $\begin{array}{c}\text { Inflamação na } \\
\text { garganta }\end{array}$ & $\mathrm{B}, \mathrm{G}$ & & & & \\
\hline
\end{tabular}




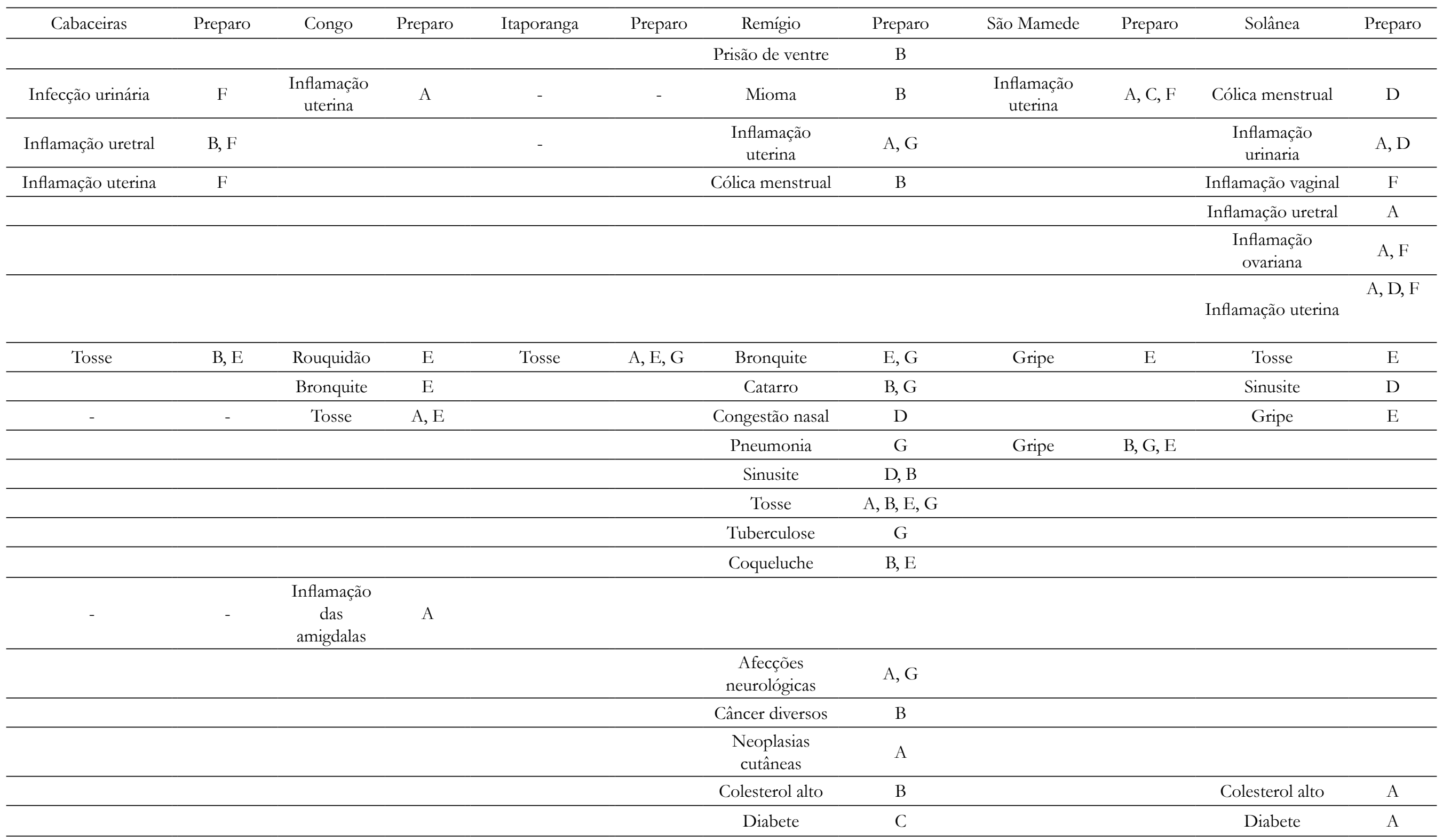




\section{ConsideraçõES FINAIS}

Os dados etnobotânicos coletados no presente estudo evidenciaram diversos usos para a aroeira, incluindo grande número de citações de uso atual, indicando a extração efetiva da espécie. Vale ressaltar que o uso da madeira, e particularmente, da casca, é sinal de alerta para sustentabilidade das populações ecológicas locais. Acredita-se que mesmo com a retirada da espécie da Red List é necessário estar sempre alerta aos seus usos e práticas de manejo.

Os dados etnobotânicos que resultam desta pesquisa podem servir como base de dados para estudos futuros que almejem por diagnósticos de padrão de uso em escalas geográficas maiores.

Para futuras investigações sugerem-se estudos com foco no monitoramento ambiental e em ações de manejo sustentável, visando a promoção a manutenção das populações ecológicos e do conhecimento local.

\section{REFERÊNCIAS}

Albuquerque UP e Andrade LHC. 2002. Uso dos recursos vegetais da Caatinga: o caso do agreste do Estado de Pernambuco (Nordeste do Brasil). Revista Interciência. 27(7):336-345.

Albuquerque UP e Oliveira RF. 2007. Is the use-impact on native Caatinga species in Brazil reduced by the high species richness of medicinal plants? Journal of Ethnopharmacology. 113: 156-170.

Albuquerque UP, Lucena RFP, Alencar NL. 2010. Métodos e técnicas para coleta de dados etnobiológicos. In: Albuquerque UP, Lucena RFP, Cunha LVFC (Eds.), Métodos e técnicas na pesquisa etnobiológica e etnoecológica. Recife: Núcleo Publicações em Ecologia e Etnobotânica Aplicada (NUPEEA). P. 39-64.

Albuquerque UP, Soldati GT, Sieber SS, Medeiros PM, Sá JC, Souza LC. 2011. Rapid ethnobotanical diagnosis of the Fulni-ô indigenous lands (NE Brazil): floristic survey and local conservation priorities for medicinal plants. Environment, Development and Sustainability. 13:277-292.

Apgaua DMG, Coelho PA, Santos RMD, Santos PF, Oliveira-Filho ATD. 2014. Tree community structure in a seasonally dry tropical forest remnant, Brazil. Cerne. 20(2):173-182.

Araújo EL, Castro CC, Albuquerque UP. 2007. Dynamics of Brazilian Caatinga: a review concerning the plants, environment and people. Functional Ecosystems and Communities. 1(1):15-28.

Arruda R. 1999. Populações tradicionais e a proteção dos recursos naturais em unidades de conservação. Revista Ambiente e Sociedade. 2(5):79-93.

Barreira S, Scolforo JRS, Botelho AS, Mello JM. 2002. Estudo da estrutura da regeneração natural e da vegetação adulta de um cerrado sensu stricto para fins de manejo florestal. Scientia Forestalis. 61:64-78.

Calixto-Júnior JTC e Drumond MA. 2014. Estudo comparativo da estrutura fitossociológica de dois fragmentos de Caatinga em níveis diferentes de conservação. Pesquisa Florestal Brasileira. 34(80):345-355.

Cartaxo SL, Souza MMA, Albuquerque UP. 2010. Medicinal plants with bioprospecting potential used in semi-arid Northeastern Brazil. Journal of Ethnopharmacology. 131:326-342. 
Carvalho JOP. 1982. Análise estrutural da regeneração natural em floresta tropical densa na região de Tapajós no estado do Pará. 128 f. Dissertação (Mestrado em Engenharia Florestal) - Setor de Ciências Agrárias, Universidade Federal do Paraná, Curitiba, 1982.

Carvalho PER. Aroeira-verdadeira. Circular Técnica 82, EMBRAPA, 2003.

Carvalho TKN, Sousa RF, Meneses SSS, Ribeiro JPO, Félix LP, Lucena RFP. 2012. Plantas usadas por uma comunidade rural na depressão sertaneja no nordeste do brasil. Revista de Biologia e Farmácia, V. Especial: 92-120.

Cavalcanti DR e Albuquerque UP. 2013. The "Hidden Diversity" of medicinal plants in northeastern Brazil: diagnosis and prospects for conservation and biological prospecting. Evidence-Based Complementary and Alternative Medicine. p.1-29.

Cuchillo HM, Puga DC, Wrage-Mönning C, Espinosa MJG, Montaño BS, Navarro-Ocaña A, Ledesma JA, Díaz MM, PérezGil RF. 2013. Chemical composition, antioxidant activity and bioactive compounds of vegetation species ingested by goats on semiarid rangelands. Journal of Animal and Feed Sciences. 22(2):106-115.

Cunha MCL, Silva Júnior MC, Lima RB. 2013. Fitossociologia do estrato lenhoso de uma Floresta Estacional Semidecidual Montana na Paraiba, Brasil. Cerne. 19(2):271-280.

Fernandes AA. 2013. Inventário do componente arbustivo-arbóreo com potencial apícola em uma área de Caatinga no município de Condado - PB. 2013. 45 f. Dissertação (Mestrado) - Curso de Programa de Pós-graduação em Sistemas Agroindustriais, Universidade Federal de Campina Grande, Pombal.

Ford RI. 1978. Ethnobotany: historical diversity and synthesis. IN: FORD R.I.; HODGE, M.; MERRIL, W. L. (EDS.). The nature and status of ethnobotany. Annals of Arnold Arboretum. Michigan: Museum of anthropology, University of Michigan. Anthropological Papers 67:33-49.

Franco EAP, Barros RFM. 2006. Uso e diversidade de plantas medicinais no quilombo Olho D’água Dos Pires, Esperantina, Piauí. Revista Brasileira de Plantas Medicinais. 8(3):78-88.

Gaino AP, Silva AM, Moraes MA, Alves PF, Moraes ML, Freitas ML, Sebbenn AM. 2010. Understanding the effects of isolation on seed and pollen flow, spatial genetic structure and effective population size of the dioecious tropical tree species Myracrodruon urundeuva. Conservation Genetics. 11(5):1631-1643.

Galvão WAR, Braz Filho R, Canuto KM, Ribeiro PRV, Campos AR, Moreira ACOM, Silva SO, Mesquita Filho FA, Santos SAAR, Melo Júnior JMA, Gonçalves NGG, Fonseca SGC, Bandeira MAM. 2018. Gastroprotective and anti-inflamatory activities integrated to chemical composition of Myracrodruon urundeuva Allemão - A conservationist proposal for the species. Journal of Ethnopharmacology. 222: 177-189.

Guerra NM, Ribeiro JPS, Carvalho TKN, Pedrosa KM, Félix LP, Lucena RFP. 2012. Usos locais de espécies vegetais nativas em uma comunidade rural no semiárido nordestino (São Mamede, Paraíba, Brasil) Revista de Biologia e Farmácia. Volume especial: p. 184-210.

Kiill LHP e Lima PCF. 2011. Plano de Manejo para Espécies da Caatinga Ameaçadas de Extinção na Reserva Legal do Projeto Salitre. Documentos 243. Embrapa. P. 55.

Leite AP, Pedrosa KM, Lucena CM, Carvalho TKN, Félix LP, Lucena RFP. 2012. Uso e conhecimento de espécies em uma comunidade rural no Vale do Piancó (Paraíba, Nordeste, Brasil). Revista de Biologia e Farmácia. Volume especial: p. 133-157. 
Leite EJ. 2002. State-of-knowledge on Myracrodruon urundewva Fr. Allemão (Anacardiaceae) for genetic conservation in Brazil. Perspectives in Plant Ecology, Evolution and Systematics. 5(3):193-206.

Lima JRF, Lima GDS, Lucena CM, Carvalho TKN, Lucena RFP. 2018. Invesntário in situ como método para a extração de recursos madeireiros na caatinga: estudo de casso no município de Cabaceiras (Paraíba, Brasil). Revista Nordestina de Biologia. 26:1-18.

Liporacci HSN, Hanazaki N, Ritter MR, Araújo EL. 2017. Where are the Brazilian ethnobotanical studies in the Atlantic forest and Caatinga? Rodriguesia, 68 (4): 1225-1240.

Lorenzi H e Matos FJA. 2002. Plantas medicinais no Brasil: nativas e exóticas. Nova Odessa: Instituto Plantarum. P. 512.

Lucena RFP, Farias DC, Carvalho TKN, Lucena CM, Vasconcelos Neto CFA, Albuquerque UP. 2011. Uso e conhecimento da aroeira (Myracrodruon urundeuva) por comunidades tradicionais no semiárido brasileiro. Sitientibus. 11(2):255-264.

Lucena RFP, Medeiros PM, Araújo EL, Alves AGC, Albuquerque UP. 2012a. The ecological apparency hypothesis and the importance of useful plants in rural communities from northeastern Brazil: an assessment based on use value. Journal of Environmental Management. 96:106-115.

Lucena RFP, Nascimeno VT, Araújo EL, Albuquerque UP. 2008. Local uses of native plants in an area of Caatinga vegetation (Pernambuco, NE-Brazil). Ethnobotany Research and Applications. 6:3-13.

Lucena RFP, Soares TC, Vasconcelos Neto CFA, Carvalho TKN, Lucena CM, Alves RRN. 2012b. Uso de recursos vegetais da Caatinga em uma comunidade rural no Curimataú paraibano (Nordeste do Brasil). Polibotánica. 34:217-238.

Machado AC, Dezan Junior E, Gomes-Filho JE, Cintra LTA, Ruviére DB, Zoccal R, Damante CA, Jardim Junior EG. 2011. Evaluation of tissue reaction to aroeira (Myracrodruon urundewva) extracts: a histologic and edemogenic study. Journal of Applied Oral Science. 20(4):414-418.

Marangon GP, Ferreira RLC, Silva JAA, Souza DF, Silva EA, Loureiro GH. 2013. Estrutura e padrão espacial da vegetação em uma área de Caatinga. Revista Floresta. 43(1):83-92.

Medeiros PM, Silva TC, Almeida ALS, Albuquerque UP. 2012. Socio-economic predictors of domestic wood use in an Atlantic forest area (North-east Brazil): a tool for directing conservation efforts. International Journal of Sustainable development \& World Ecology. 19(2).

Monteiro JM, Araújo EDL, Amorim ELC, Albuquerque UPD. 2012. Valuation of the aroeira (Myracrodruon urundewva Allemão): perspectives on conservation. Acta Botanica Brasilica. 26(1):125-132.

NATURE, International Union for Conservation of. Red List. 2015. Disponível em: < http://www.iucnredlist.org/ amazing-species>. Acesso em: 05 jan. 2015.

Nobre-Júnior HV, Oliveira RA, Maia FD, Nogueira MAS, Moraes MO, Bandeira MAM, Andrade GM, Viana GSB. 2009. Neuroprotective effects of chalcones from Myracrodruon urundewva on 6-hydroxydopamineinduced cytotoxicity in rat mesencephalic cells. Neurochemical Research. 34:1066-1075.

Oliveira FC, Albuquerque UP, Fonseca-Kruel VS, Hanazaki N. 2009. Avanços nas pesquisas etnobotânicas no Brasil. Acta Botanica Brasilica. 23(2):590-605. 
Oliveira FP, Souza AL, Fernandes Filho EI. 2014. Caracterização da monodominância de aroeira (Myracrodruon urundewva Fr. All.) no município de Tumiritinga-MG. Ciência Florestal. 24(2): 299-311.

Oliveira RLC, Lins Neto EMF, Araújo EL, Albuquerque UP. 2007. Conservation priorities and population structure of woody medicinal plants in area of Caatinga vegetation (Pernambuco State, NE Brazil). Environmental Monitoring and Assessment. 132:189-206.

Oliveira FA, Rorato VC, Almeida-Apolonio AA, Rodrigues AB, Barros AL, Sangalli A, Arena AC, Mota JS, Grisolia AB, Oliveira KMP. 2017. In vitro antifungal activity of Myracrodruon urundeuva Allemão against human vaginal Candida species. Anais da Academia Brasileira de Ciências. 89 (3 Suppl): 2423-2432.

Paes JB, Morais VDM, Lima CRD. 2004. Resistência natural de nove madeiras do semiárido brasileiro a fungos xilófagos em condições de laboratório. Revista Árvore. 28(2):275-282.

Pedrosa KM, Lima EQ, Lucena CM, Carvalho TKN, Ribeiro JES, Marín EA, Oliveira RS, Alves RE, Silva SM, Cruz DD, Lucema RFP. 2015. Local botanical jnowledge about Sideroxylon obtusifolium (Roem. \& Schult) T.D. Penn. In rural communities in the semiarid refion of Brazil. Ethnobotany research applications. 14:463-477.

Pereira PS, Barros LM, Brito AM, Duarte AE, Maia AJ. 2014. Uso da Myracrodruon urundewva Allemão (aroeira do sertão) pelos agricultores no tratamento de doenças. Revista Cubana de Plantas Medicinales. 19(1):51-60.

Ramos MA, Medeiros PM, Almeida ALS, Feliciano ALP, Albuquerque UP. 2008a. Use and knowledge of fuelwood in an area of Caatinga vegetation in NE Brazil. Biomass e Bioenergy. 32: 510-517.

Ramos MA, Medeiros PM, Almeida ALS, Feliciano ALP, Albuquerque UP. Can wood quality justify local preferences for firewood in an area of Caatinga (Dryland) vegetation? Biomass and Bioenergy. 32(4): 503-509.

Rizzini CT. 1970. Árvores e arbustos de cerrado. Revista Rodriguésia. 26(38):63:77.

Rodrigues RRR e Gandolfi S. 2000. Conceitos, tendências e ações para recuperação de florestas ciliares. In: RODRIGUES, R. R. R. e LEITÃO-FILHO, H. F. (Eds.) Matas ciliares: conservação e recuperação. São Paulo: Editora da USP. p. 235-247.

Rodriguez SC, Alvarado JC, Espírito-Santo MM, Nunes URF. 2017. Myracrodruon urundenva Fr. Allemão (Aroeira tree) populations dynamics, diameter growth rate and its potential for sustainable manegement in sucessional tropical dry forests of Brazil. Revista Árvore. 41(3).

Sá RA, Argôlo ACC, Napoleão TH, Gomes FS, Santos NDL, Melo CML, Albuquerque AC, Xavier HS, Coelho LCBB, Bieber LW, Paiva PMG. 2009. Antioxidant, fusarium growth inhibition and nasutitermes corniger repellent activities of secondary metabolites from Myracrodruon urundewva heartwood. International Biodeterioration e Biodegradation. 63:470-477.

Sá RA, Napoleão TH, Santos NDL, Gomes FS, Albuquerque AC, Xavier HS, Coelho LCBB, Bieber LW, Paiva PMG. 2008. Induction of mortality on Nasutitermes corniger (Isoptera, Termitidae) by Myracrodruon urundeuva heartwood lectin. International Biodeterioration e Biodegradation. 62:460-464.

Salomão GB, Fernandes SSL, Pereira ZV, Nascimento JS, Moitinho MR, Padovan MP. 2014. Estoque de carbono por espécies arbóreas em um sistema agroflorestal biodiverso em Dourados, Mato Grosso do Sul. Cadernos de Agroecologia. 9(4):1-11.

Scherer A, Maraschin-Silva F, Baptista LRM. 2014. Regeneração arbórea num capão de restinga no Rio Grande do Sul, Brasil. Iheringia Série Botânica, 62(1): 2. 
Silva FDS, Ramos MA, Hanazaki N, Albuquerque UP. 2011. Dynamics of traditional knowledge of medicinal plants in a rural community in the brazilian semi-arid region. Brazilian Journal of Pharmacognosy. 21(3):382-391.

Silva HCH, Caraciolo RLF, Marangon LC, Ramos MA, Santos LL, Albuquerque UP. 2014. Evaluating different methods used in ethnobotanical and ecological studies to record plant biodiversity. Journal of Ethnobiology and Ethnomedicine. 10(1):1-11.

Silva KE, Martins SV, Santos NT, Ribeiro CAAS. 2009. Padrão espacial de espécies arbóreas tropicais. In: MARTINS, S. V (Eds.). Ecologia de Florestas Tropicais. Viçosa: Ed. UFV. p. 216 - 241.

Silva MIG, Gondim APS, Nunes IFS, Sousa FCF. 2006. Utilização de fitoterápicos nas unidades básicas de atenção à saúde da família no município de Maracanaú (CE). Brazilian Journal of Pharmacognosy. 16(4):455-462.

Silva MSP, Brandao DO, Chaves TP, Formiga Filho AL, Costa EMMDB, Santos VL, Medeiros ACD. 2012. Study bioprospecting of medicinal plant extracts of the semiarid northeast: contribution to the control of oral microorganisms. Evidence-Based Complementary and Alternative Medicine. p.1-6.

Silva N, Lucena RFP, Lima JRF, Lima GDS, Carvalho TKN, Sousa Júnior SP, Alves CAB. 2014. Conhecimento e uso da vegetação nativa da Caatinga em uma comunidade rural da Paraíba, Nordeste do Brasil. Boletim do Museu de Biologia Mello Leitao. 34:5-37.

Silva S, Anselmo MGV, Dantas WM, Rosa JH, Nunes EM, Soares JP, Alves CAB 2014a. Conhecimento e uso de plantas medicinais em uma comunidade rural no município de Cuitegi, Paraíba, Nordeste do Brasil. Gaia Scientia, 8(1): 248-265.

Silva JMC, Leal IR, Tabarelli, M (ed.). Caatinga: The largest tropical dry forest region in South America. Springer International Publishing, 2017.

Silva-Luz CL, Pirani JR. Anacardiaceae in lista de espécies da flora do Brasil. Jardim Botânico do Rio de Janeiro. Disponível em: <http://floradobrasil.jbrj.gov.br/jabot/floradobrasil/fb4394>. Acesso em: 31 mar. 2015

Silva LLH, Oliveira E, Calegari L, Pimenta MAC, Pimenta AS, Dantas MKL. 2018. Características energéticas do carvão vegetal de Aroeira (Myracrodruon urundeuva Allemão) e Leucena (Leucaena leucocephala (Lam.) R. de Wit.). Ciência Florestal, Santa Maria. 28(1): 412-419.

Siqueira CFDQ, Cabral DLV, Peixoto Sobrinho TJDS, Amorim, ELC, Melo JG, Araújo TADS, Albuquerque UP. 2012. Levels of tannins and flavonoids in medicinal plants: evaluating bioprospecting strategies. Evidence-Based Complementary and Alternative Medicine. P.1-7.

Sousa RF, Gomes DS, Leite AP, Silva S. 2012. Estudo etnobotânico de Myracrodruon urundeuva Allemão no Vale do Piancó (Paraíba, Nordeste, Brasil). Revista de Biologia e Farmácia, 7(1):72-83.

Specht MJ, Pinto SRR, Albuqueque UP, Tabarelli M, Melo FP. 2015. Burning biodiversity: fuelwood harvesting causes forest degradation in human-dominated tropical landscapes. Global Ecology and Conservation. 3:200-209.

Viana GSB, Bandeira MAM, Matos FJA. 2003. Analgesic and anti-inflammatory effects of chalcones isolated from Myracrodruon urundewva Allemão. Phytomedicine. 10:189-195.

Yunes RA, Pedrosa RC, Cechinel Filho V. 2001. Fármacos e fitoterápicos: a necessidade do desenvolvimento da indústria de fitoterápicos e fitofármacos no Brasil. Química Nova. 24(1):147-152. 